\title{
Study on the Competence of Biology Pharmacy Industry in Xi'an High-tech Zone
}

\author{
XingLi Sun \\ Beijing Jiao Tong University \\ Beijing, China \\ 12120760@bjtu.edu.cn
}

\author{
Yingqi Liu \\ Beijing Jiao Tong University \\ Beijing, China \\ liuyq@bjtu.edu.cn
}

\author{
Su Yang \\ Xi'an High-tech Zone biomedical Office \\ Xi'an, China \\ yangsu@xdz.gov.cn
}

\begin{abstract}
Based on Michael Potter's " Diamond Theory ", the paper takes biology pharmacy industry in Xi'an High-tech Zone as research object and constructs an evaluation system of industry competence. In addition, the paper applies factor analysis to deal with data. Based on the results, the paper extracts five main factors: external support factor,supply chain factor,facilities factor,human resource factor. According to the calculation data, the paper makes some analysis and put forward with some suggestions to promote the competence of biology pharmacy industry.
\end{abstract}

Keywords-biology pharmacy industry; industry competence; diamond theory

\section{INTRODUCTION}

In the world today, biology pharmacy industry become has become an emerging strategic industry, which mainly includes the biological medicine, biological mechanical, biological agriculture, environmental protection industry. the development of biological pharmacy industry not only help to improve human health, but help to solve many social problems, such as environmental protection, food shortage, energy shortage, etc. In the term of development level, the biological pharmacy industry of USA is most advanced. As a developing country, China gives great support to the bio-industry among the 11th Five-Year Plan period and treats the bio-industry as a key development industry. Now, China's pharmaceutical industry has formed a certain pattern. As one of China's first state-level high-tech zones, xi 'an high-tech zone takes biological medicine industry as one of the four leading industries. After unremitting efforts, the revenue of biological medicine industry has reached 23.84 billion yuan and the growth rate reached $30.67 \%$. In order to study the the competitiveness of the pharmaceutical industry, according to the diamond theory, in this paper, the paper construct the competitiveness evaluation index system. Based on the principle of qualitative and quantitative, researchers design questionnaire and use the factor analysis of SPSS software technology to analysis the questionnaire results.

\section{THEORETICAL BASIS}

\section{A. Michael Porter's Diamond Theory}

"Diamond Model" was proposed by Michael Port, a famous strategic management scientist of Harvard Business School. The model is applied to analyze why some industries in a country has the strong competitiveness in the world. Porter suggested that the competitiveness of some industries is relied on four factors, which have mutual effects.

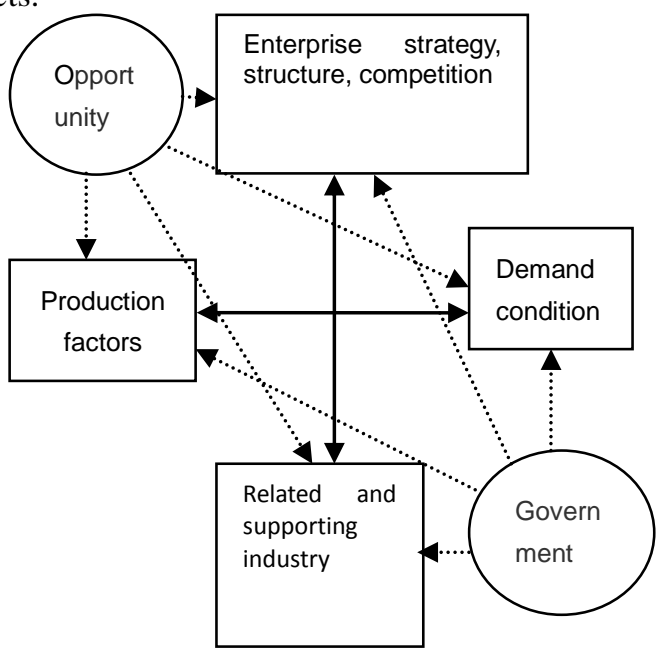

Figure 1. Diamond theory mode

The four elements of the theory contain: Production factors--human resources, natural resources, capital resources and infrastructure; Demand conditions -- domestic market demand; Related industries and support industries - whether the upstream industries and related industries have international competitiveness; Enterprise strategy, structure, performance of competitors.

In addition to the four elements, there are two variables: the government and opportunities. Opportunity is out of control and the influence of government policy can't be ignored. In terms of enterprises' development, there are several possible conditions for opportunity: Basic 
technology inventions; Gap in traditional techniques; External cause resulting in production cost increase (such as the oil crisis); a major change in financial markets or the exchange rate; A surge in market demand; The important decisions of the government; The war. What the government can do is to provide resource for enterprises and create an environment for industrial development. Government influence the competitive advantage through the policy options and the influence is indirectly by the other four key factors

\section{B. The Applications of "Diamond Model" in the Study of Industry}

Porter's "Diamond model" is wildly used in many industries, such as industrial, commercial, tourism, construction, agriculture, biological medicine industry and other fields. In the area of competitive advantage research, "Diamond model" is supported by many scholars in academia.

Some foreign scholars joined the other important factors in the "Diamond model", which makes the "Diamond model" more complete and practical. For example, Naserbakht, Mohammad combined the Diamond model and SWOT method to analyze the level of the competiveness of Iranian Science and Technology Park. Domestic: Inspired by "Diamond model" of Porter , Dai Yang applied capital reorganization to enhance industrial competitiveness of China's publishing industry; Zhang Haiyan, Wu Yingli used "diamond model" to analyze the competitive advantage of the Ponkan industry in Xiangxi and proposed that the corresponding advantage should be taken to help the Ponkan industry develop into a local pillar industry.

There are many scholars applied "Diamond model" to the pharmaceutical industry, such as: Huang Xiaoqian used diamond theory to analyze the competitiveness of biological medicine industry of Singapore, and constructed the diamond model of biological medicine industry in Singapore. The model analyze the competitiveness of Singapore's biological medicine industry from capital and talent, industrial concentration, international demand, innovation ability, market opportunities and government policy and discuss the possible challenges in the future. Zhao Bing, Zhang Dongsheng, Zhao Yongzheng, Liu Min, Chu Shuzhen applied "Diamond model" to regional medicine industry competitiveness research. Base on the model they studied pharmaceutical industry competitiveness in Shijiazhuang and Jiangsu Province and treat innovation as the research priorities of opportunity.

Current research suggests that porter's "diamond model" theory is suitable for research and analysis on the industrial advantages. Therefore, based on the "diamond model", the paper build industry competitiveness evaluation system to study and analyze the medicine industry competitiveness of xi 'an high-tech zone.

\section{INDUSTRIAL COMPETITIVENESS EVALUATION MODEL BUILDING}

\section{A. Industrial Competitiveness Evaluation Index Building}

On the basis of other scholars' research, following the three major principles of "diamond theory": stability, availability, maneuverability, the paper constructs the industry competitiveness evaluation index system. The index system includes six first-level indicators and 16 second-level indicators, as shown in table 1.

TABLE I. INDUSTRY COMPETITIVENESS EVALUATION INDEX SYSTEM

\begin{tabular}{|c|c|}
\hline first-level indicators & second-level indicators \\
\hline \multirow{3}{*}{ Production factors } & P1 the human resources \\
\hline & P3 Technical resources condition \\
\hline & P4 Transition condition \\
\hline Market demand & P2 Market demand \\
\hline \multirow{5}{*}{$\begin{array}{l}\text { Relevant and } \\
\text { support industries }\end{array}$} & P5 Intermediary agencies \\
\hline & P6 The loan difficulty \\
\hline & P11 The location of the value chain \\
\hline & $\begin{array}{l}\text { P9 Upstream or downstream industry } \\
\text { competitive advantage }\end{array}$ \\
\hline & P16 Sales network expansion \\
\hline \multirow{4}{*}{$\begin{array}{c}\text { Enterprise strategy, } \\
\text { structure and } \\
\text { horizontal } \\
\text { competition } \\
\end{array}$} & P8 Competition between enterprises \\
\hline & P7 Cooperation between enterprises \\
\hline & P10 Degree of industrial cluster \\
\hline & P12 Alternatives \\
\hline \multirow[b]{2}{*}{ The government } & P13 The government support \\
\hline & $\begin{array}{l}\text { P14 The improvement of the } \\
\text { investment environment }\end{array}$ \\
\hline Opportunity & $\begin{array}{l}\text { P15 Industry development } \\
\text { opportunities }\end{array}$ \\
\hline
\end{tabular}

IV. FACTOR ANALYSIS MODEL AND THE DATA

\section{A. Evaluation Model}

Now, there are many index evaluation methods, such as expert investigation method, analytic hierarchy process (ahp), etc. Without loss of much variable information, Factor analysis converts multiple measured variables into a few of unrelated comprehensive indexes, which reflect and explain the relationship between the measured variables. The principle is that through studying the internal dependencies between the variables in the evaluation index system, to explore the basic structure of the observation data, several hypothetical variables can reflect the main information of original variables. In addition, the several hypothetical variables are used to present basic data structure, which are the elements of comprehensive evaluation index system, ruling out similar indicators among samples. The principle of analysis method is to reduce the dimension related industry competitiveness evaluation index vectors and get less vectors. Based on the method, every contribution ratio of the comprehensive factor is treated as weigh to construct a comprehensive evaluation model to judge the enterprise environment level. the computation formula of comprehensive score is as follows:

$$
\mathrm{F}=\sum_{\mathrm{i}=1}^{\mathrm{n}} \operatorname{an} \mathrm{Fi}
$$


In the formula, ai represents weight, Fi represents each factor score. In order to get index weight, it needs multiple linear transformation and data operation, not only avoiding the influence of subjective factors, but eliminating repeated information among the index .In addition, it help to simplify data and seize the essence, making the research objective and reasonable.

\section{B. Data Acquisition}

According to the industry's competitiveness evaluation index system, based on the principle of qualitative and quantitative, the researchers designed and handed out questionnaires to several pharmaceutical enterprises. the data of 200 enterprises are collected, there are 117 valid questionnaires. According to the registered capital, the enterprises are divided into three categories: large enterprises, medium-sized enterprises and small businesses.

\section{V.THE RESULTS OF FACTOR ANALYSIS}

In this paper, researchers used statistical software SPSS19 analysis software to standardize the raw data and $\mathrm{KMO}$ value is 0.756 and Sig value is 0 , which suggested that the sample data is enough for factor analysis. Principal component extraction rate and the cumulative variance follows in table 2 .

TABLE II. THE PRINCIPAL COMPONENT ANALYSIS OF THE VALUE AND CONTRIBUTION RATE

\begin{tabular}{|c|c|c|c|c|c|c|c|c|c|}
\hline \multirow[b]{2}{*}{ Element } & \multicolumn{3}{|c|}{ The initial eigenvalue } & \multicolumn{3}{|c|}{ Extraction squares sum loading } & \multicolumn{3}{|c|}{ Rotating squares sum loading } \\
\hline & Total & $\begin{array}{l}\text { Variance } \\
\text { contribution rate } \\
\%\end{array}$ & $\begin{array}{l}\text { Cumulative } \\
\%\end{array}$ & Total & $\begin{array}{l}\text { Variance } \\
\text { contribution rate } \\
\%\end{array}$ & $\begin{array}{l}\text { cumulative } \\
\%\end{array}$ & Total & $\begin{array}{l}\text { Variance } \\
\text { contribution rate } \\
\%\end{array}$ & $\begin{array}{l}\text { Cumulativ } \\
\text { e }\end{array}$ \\
\hline 1 & 4.539 & 28.371 & 28.371 & 4.539 & 28.371 & 28.371 & 3.142 & 19.636 & 19.636 \\
\hline 2 & 1.742 & 25.886 & 54.257 & 1.742 & 25.886 & 54.257 & 2.018 & 27.611 & 47.246 \\
\hline 3 & 1.365 & 13.529 & 67.786 & 1.365 & 13.529 & 67.786 & 1.918 & 16.990 & 64.237 \\
\hline 4 & 1.300 & 9.127 & 76.913 & 1.300 & 9.127 & 76.913 & 1.634 & 11.214 & 75.450 \\
\hline 5 & 1.051 & 8.566 & 85.479 & 1.051 & 8.566 & 85.479 & 1.285 & 10.029 & 85.479 \\
\hline 6 & .914 & 2.714 & 88.193 & & & & & & \\
\hline
\end{tabular}

TABLE III. ROTATING COMPONENT MATRIX

\begin{tabular}{c|c|c|c|c|c}
\hline \multirow{2}{*}{ Indicator } & \multicolumn{5}{|c}{ The principal component } \\
\cline { 2 - 6 } & $\mathrm{F} 1$ & $\mathrm{~F} 2$ & $\mathrm{~F} 3$ & $\mathrm{~F} 4$ & $\mathrm{~F} 5$ \\
\hline P1 & .218 & .233 & .489 & -.090 & .524 \\
P2 & .358 & .358 & .503 & -.083 & -.260 \\
P3 & .132 & .130 & .787 & .154 & -.041 \\
P4 & .089 & .035 & .759 & -.002 & .046 \\
P5 & .598 & .012 & .229 & .004 & -.188 \\
P6 & .523 & .149 & .219 & .321 & -.609 \\
P7 & .239 & .086 & .022 & .556 & .118 \\
P8 & .117 & .564 & .062 & .297 & .006 \\
P9 & .080 & .808 & .055 & .008 & .020 \\
P10 & .150 & .291 & .102 & .689 & -.054 \\
P11 & -.078 & -.772 & -.021 & .078 & .030 \\
P12 & -.019 & -.088 & .162 & .471 & .692 \\
P13 & .787 & -.047 & .140 & .098 & .107 \\
\hline & .797 & .328 & .181 & -.019 & -.024 \\
P16 & .578 & .361 & .359 & -.103 & -.148 \\
P16 & .173 & -.109 & -.066 & -.047 \\
\hline
\end{tabular}

According Table II, we selected the top five factors as the main components. The cumulative variance is $85 \%$. The five principal components represent $85.479 \%$ of the original information, which better explain the original variables. The five principal components are named the F1, F2, F3, F4, F5.

In order to understanding the meaning of the principal components, it is needed to study the rotating component matrix (e.g., table 3) Obviously, P5,P6,P13,P14,P15,P16 have more contribution rate on $\mathrm{F} 1$, which is named the external support factor; P9,P8,P11 have more contribution rate on $\mathrm{F} 2$, which is named the supply chain factor; P2,P3,P4 have more contribution rate on $\mathrm{F} 3$, which is named the industrial supporting factor; P7,P10 have more contribution rate on $\mathrm{F} 4$, which is named the industry specialization factor; the factor F5 can be referred to as the human factor.

Based on the computation formula of comprehensive score, it is known: $\mathrm{a} 1=0.2297, \mathrm{a} 2=0.323, \mathrm{a} 3=0.1987$, $\mathrm{a} 4=0.1312, \mathrm{a} 5=0.1173$. Composite scores formula follows:

\section{$\mathrm{F}=0.229 * \mathrm{~F} 1+0.323 * \mathrm{~F} 2+0.1987 * \mathrm{~F} 3+0.1312 * \mathrm{~F} 4+0.1173 * \mathrm{~F} 5$}

According to the enterprise registered capital, there are 39 large enterprises with registered capital more than 20 million, 35 medium-sized enterprises between 20 million and 5 million, 43 small businesses below 5 million. Calculate the composite score of enterprises and sort, the result is following. 
TABLE IV. THE COMPREHENSIVE SCORE AND RANKING

\begin{tabular}{|c|c|c|c|c|c|c|c|c|c|c|c|c|}
\hline \multirow{2}{*}{ enterprise type } & \multicolumn{2}{|c|}{$F 1$} & \multicolumn{2}{|c|}{$F 2$} & \multicolumn{2}{|c|}{$F 3$} & \multicolumn{2}{|c|}{$F 4$} & \multicolumn{2}{|c|}{$F 5$} & \multicolumn{2}{|c|}{$\bar{F}$} \\
\hline & score & rank & score & rank & score & rank & score & rank & score & rank & score & rank \\
\hline large enterprises & 0.77 & 2 & 1.04 & 2 & -0.8 & 1 & 0.16 & 1 & -1.33 & 2 & 0.72 & 2 \\
\hline medium-sized & 1. 66 & 1 & 2.13 & 1 & -2.34 & 3 & -0.14 & 3 & -1.35 & 3 & 0.83 & 1 \\
\hline enterprises & & & & & & & & & 5 & & & \\
\hline small businesses & -1.75 & 3 & 0.3 & 3 & -0.87 & 2 & -0.35 & 2 & 2.15 & 1 & -0.38 & 3 \\
\hline
\end{tabular}

\section{CONCLUSION AND SUGGESTIONS}

1) The scores of F1 and F2 are similar. From the F1, it can be seen medium-sized enterprises and large enterprises get more external support; on the contrast, small businesses get less support. Reason may come from the various respects, for example, when the Government makes policy, it gives preferential policies to large and medium enterprise and ignores the development of small enterprises. In addition, some financial institutions are willing to invest in large enterprises and medium-sized enterprises. Medium-sized enterprises have better external support conditions than large enterprises, which indicate medium-sized enterprises have greater space for development in the future. Based on the F2, large and medium-sized enterprises have more initiative in deal with small businesses 。 Small businesses can only depend on large enterprise, so their competition ability is weak.

2) According to the score of F3, it's seen that all scores are negative. Obviously, most companies are dissatisfied with the supporting services. Government could perform well in policy support, but bad in certain infrastructure. In recent years, Medicine industry develops rapidly and the park continues to expand. In addition, the overall technology level of China is not high. As a representative of the high-tech industry, the pharmaceutical industry development level of our country is low. The research results show that the pharmaceutical enterprises of xi 'an high-tech zone need to increase investment in new products and new technology.

3) According to the F4, we know that only large enterprises score is positive, small and medium enterprises are negative. The data result shows that large companies tend to cooperate with each other to develop the market and study new products, which not only reduce the failure rate in the development of the market, but also can reduce the costs of enterprise research and development, especially for innovative products. For F5, only small businesses get higher scores, large enterprises and medium-sized enterprises' scores are negative, which estimates that the human resources couldn't meet the needs of large enterprises and medium-sized enterprises. Compared with the staff of small business, the people enterprises and medium-sized enterprises need should have higher education level, more professional knowledge and stronger study ability. Now, our country is lack of biological medicine professionals. Therefore education departments should pay more attention to the professional an cultivate more biological medicine professionals.

4) The composite score of the three types of enterprises suggests that the development environment of large enterprises and medium-sized enterprises is better, on the contrary, the development condition of small enterprises is worse.

\section{REFERENCES}

[1] Xu Guosheng. China's Biomedical Industry Development Status and Strategy[J]. Practical Journal of Hepatology, 2012,15(5):478-480.(in Chinese)

[2] Wang Jiating. The Industrial area Agglomeration Measure: An Empirical Study of China's based on Pharmaceutical Industry[J]. Innovation, 2012,6(41):37-41

[3] Zhang Ying, Liu Yong, Wang Xinxin. China Biological Medicine Industry Opening Innovation Research [J]. Modern Commerce Industry, 2012(12)

[4] Li Xiaohe. The Rapid Rise of Singapore's Biomedical Industry and its Implication for China $[\mathrm{J}]$. Economic Management and Reform and Development, 2012(8)176-177.

[5] Liu Yingqi. The Development and Application of the Diamond Theory[J]. China Soft Science,2003(10):139-145.

[6] Dai Yang. Recapitalization Promoting China's Publishing Industry competitive Advantage Research[J].Publishing Research,2012(10):139-145. 